\title{
Characterization of carbonate rocks using seismic wave for tunnel design stability
}

\author{
Hairin Taha ${ }^{1}$, Nurul Atiqah Dzulkifli ${ }^{2}$, Rohayu Che Omar $^{1 *}$, Ratih Fitria Putri ${ }^{3 *}$ Rasyikin Roslan ${ }^{1}$ and Intan Nor Zuliana \\ Baharuddin ${ }^{1}$ \\ ${ }^{1}$ Institute of Energy Infrastructure, Universiti Tenaga Nasional, 43000 Kajang, Malaysia \\ ${ }^{2}$ College of Graduate Studies, Universiti Tenaga Nasional, Kajang, 43000, Malaysia \\ ${ }^{3}$ Department of Environmental Geography, Faculty of Geography, Gadjah Mada University, Yogyakarta, 55281, Indonesia
}

\begin{abstract}
The design and construction of a tunnel depends on the mechanical properties of the rock mass around the tunnel. Seismic method can be used to characterize the dynamic properties of rocks. The technique is mostly conducted in geophysical surveys and geotechnical investigations. The method utilizes reflected sound waves that can be used to describe the dynamic properties of rocks. Physical properties of carbonate rocks such as water content, density, hardness, permeability, porosity, wave velocity and abrasivity can be assessed and estimated using P-wave velocity. One of the important characteristics in rock is its ability to remain stable. In this research, seismic refraction survey was applied to measure the strength of carbonate rocks for tunnel stability design. The findings revealed that the regression between the primary velocity and the uniaxial compressive strength $\mathrm{R}^{2}$ was 0.8592 , indicating that the rock was firm and solid. Observation by physical visual test showed that the rock samples with yellowish-grey and light grey colours were categorized in the weathering grade II and III, respectively. The results have concluded that the rocks in the proposed area met the full requirements for tunnelling construction.
\end{abstract}

\section{Introduction}

The materials composed in an intact rock can be quantified and characterized through physical test or laboratory test. In general, rock materials can be categorized into two classification, physical and mechanical properties. The properties of rock materials are almost the same to the physical content of rock that form minerals and variety of mineral bonding. The physical properties of rock materials include water content, density, hardness, permeability, porosity, wave velocity and abrasivity $[1,2]$ whereas the strength of rock is classified under mechanical properties. Before initiating any construction, a preliminary ground investigation has to be conducted to get information on the soil profile and condition in the proposed area so that safety measures and precautions can be exercised during the construction period.

In this case, various ground investigations were conducted along the MRT lines during the early phase of construction that consisted of 400 boreholes and geophysical surveys. During the preliminary soil sampling, it was noted that the construction area was formed from the merging of Kenny Hills sedimentary rock and KL Limestone formation which was composed of highly endured karst [3]. Nevertheless, the rocks at the KL Limestone region consist of uncertain formation of karstic features such as steeply inclined bedrock, cavities, pinnacles and floater which are more challenging that needed extra inspection and procedures [4].

This zone has an outrageous karstic feature containing marbles and cavities which needs to be considered and evaluated by the specialists or engineers in term of ground condition and the rock properties before doing underground construction. In this case, several tests were required to analyse the rock strength before embarking on any construction to determine if the rock condition and its physical properties has any effect on the stability of the tunnel that might create any negative impact or outcome.

This paper describes an in situ study and laboratory testing of rock strength for tunnel stability design by characterizing the properties of rock samples in the Kuala Lumpur Limestone formation. The parameters of the rock mass were studied and analysed to determine if the rock mass will directly affect the wall stability of tunnel during the construction. The data was obtained by in-situ testing and performing laboratory test to determine the strength of intact rock. Geophysical investigation was carried in the field while the borehole samples were tested in the laboratory. Several testing including destructive and undestructive tests were conducted to test the rock strength.

\footnotetext{
*Corresponding author: rohayu@,uniten.edu.my, ratihfitria.putri@ugm.ac.id
} 


\section{Methodology}

\subsection{Experimental site}

In this work, the experimental site was at Bukit Bintang station which was located between two rock formations, KL Limestone Formation and Kenny Hills formation that largely consists of karstic limestone [5]. It was observed that the limestone mass was covered with subsurface cavities and underground chambers that can be potentially dangerous for tunnelling excavation and construction. To ensure the safety of the tunnelling process, safety measures and extra precaution need to be considered to avoid unfortunate incidents. Figure 1 and Figure 2 show the study area along the Kenny Hills and KL Limestone formation where the proposed underground tunnel would be constructed.

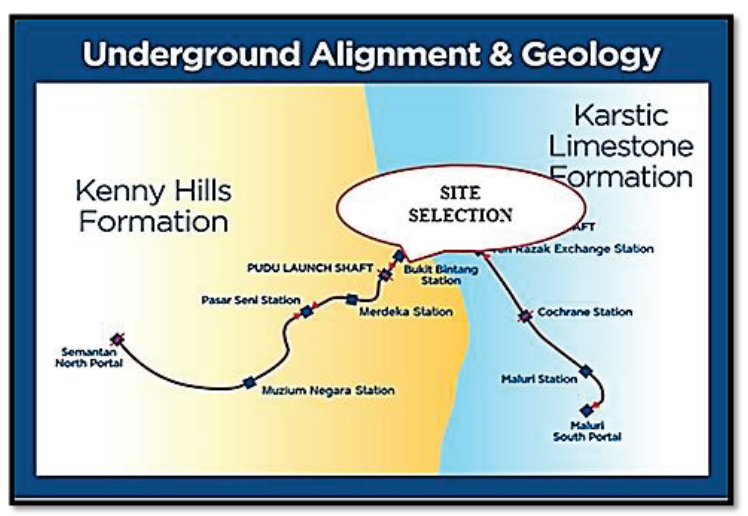

Fig. 1. Study location

\subsubsection{Geophysical assessment}

Geophysical survey is commonly used to investigate the underground structures of tunnelling prior to any construction works to study the underground subsurface and the rock properties. Seismic refraction and resistivity were carried out for cross-hole tomography analysis to investigate the rock mass [6]. The seismic refraction survey is a widely used method in geophysical technique to explore the subsurface condition and characteristics by utilizing the refraction of seismic waves whereas the electrical resistivity technique is used to characterize the sub-surface materials based on their electrical properties. In this work, geophysical survey was conducted along Line 1 to collect information on the physical properties of the rocks. Figure 3 shows the flowchart of the research process.

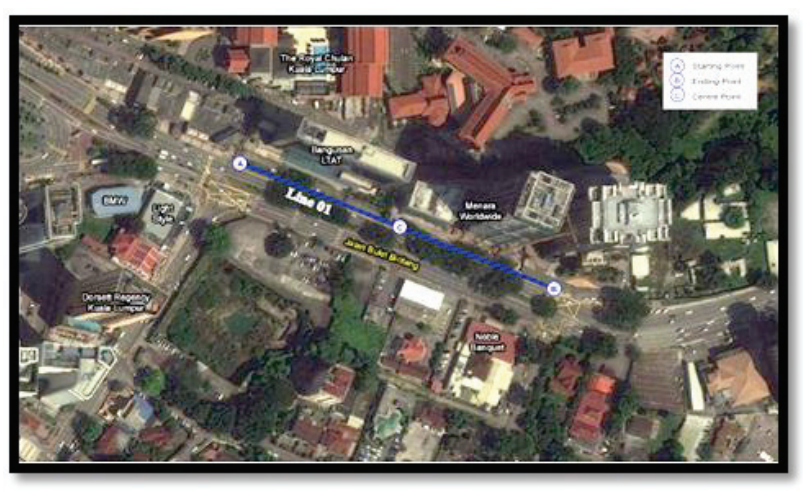

Fig. 2. Geophysical investigation on Line 1.

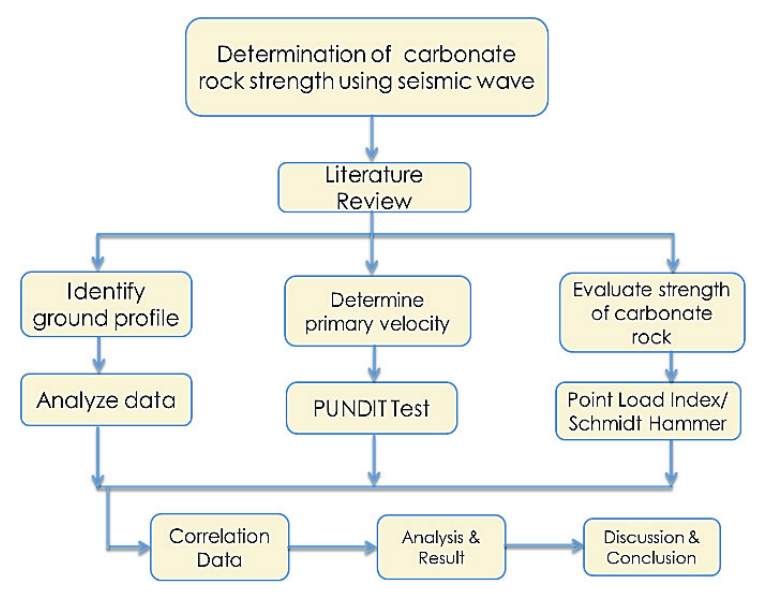

Fig. 3. Flow chart of the study.

\subsubsection{Sample preparation}

Figure 4 shows the samples of rock coring (limestone) that belong to two different boreholes which were CUB 040 and CUB 073 that were acquired from the site. Each of the rock samples were cut approximately $150 \mathrm{~mm}$ following ASTM standard using a diamond cutter, as the rock coring diameter was $55 \mathrm{~mm}$. There were two intact rocks in box CUB 040 and other 13 samples from box CUB073. Most of the rocks in box CUB 040 had cracks and defects. 

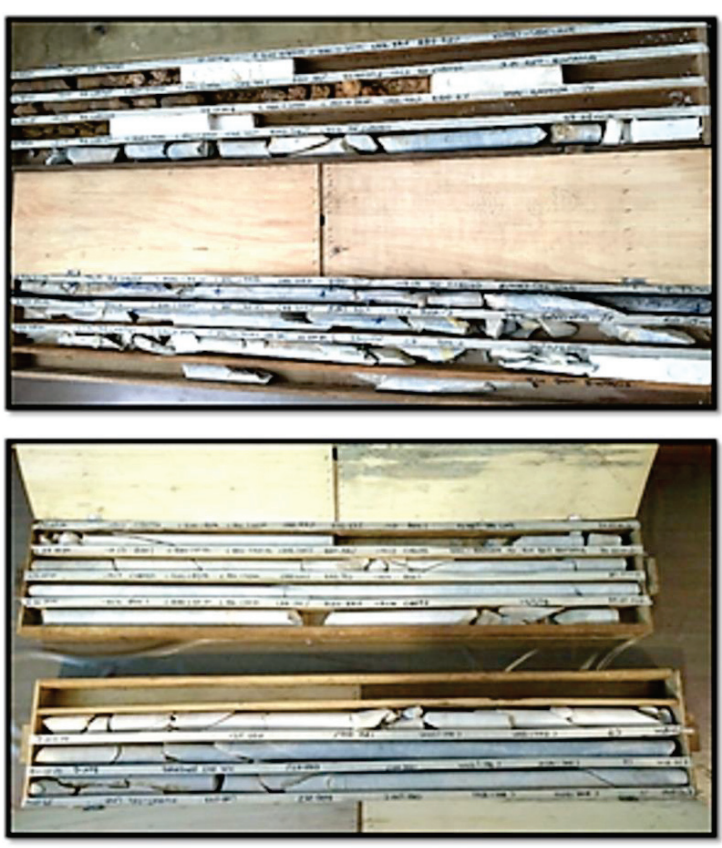

Fig. 4. Rock coring samples from borehole CUB 040 and CUB 073.

\subsubsection{UItrasonic Wave Velocity}

Ultrasonic pulse velocity (UPV) is a non-destructive method that measure the primary velocity of an electronic pulse that pass through the rock (Figure 5). It is also known as PUNDIT test. The test was run by putting the connector between the transducer and the receiver on contact to achieve zero reading. When it was stabilized, the aluminium cylinder was switched with the real specimen samples. Both transducer - receiver was positioned at the outer surface of the rock samples. Data was recorded when the reading in the meter shows a constant value. The primary velocity $(\mathrm{Vp})$ was obtained by dividing the length of samples with average transit time.

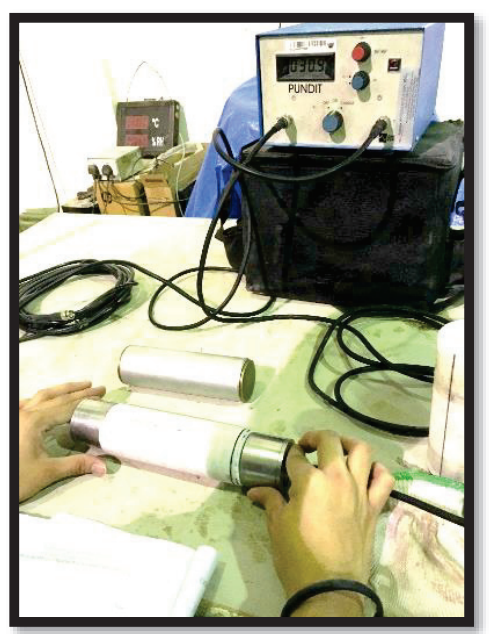

Fig. 5 UPV test.

\subsubsection{Schmidt hammer Test}

The Schmidth hammer test or rebound hammer was used to measure the uniaxial compressive strength (UCS) of the rock samples (Figure 6). The test was conducted according to ASTM standard instead of ISRM standard because the core diameter of the specimen was less than $55 \mathrm{~mm}$ [8]. In this test, the hammer was firmly held perpendicular to the length of the specimens, at about $90^{\circ}$ normal. The surface contact is represented by the length of sample. The data was calculated by basic mathematical statistic due to reading variabilities of each sample. The average reading of rebound hammer, was taken approximately 10 times around the surface contact of each sample.

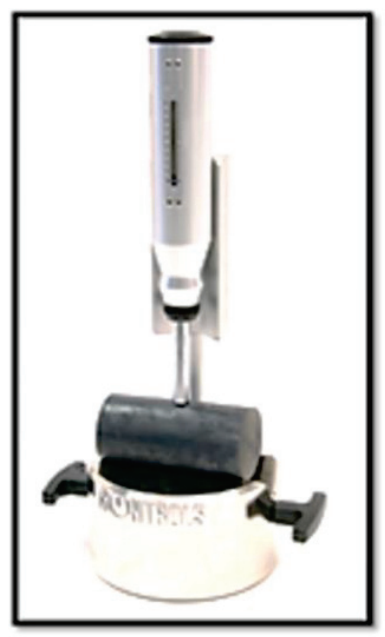

Fig. 6. Schmidt hammer test

\subsubsection{Point Load test}

The uniaxial compressive strength (UCS) of the rock samples was measured by Point Load test which is a destructive test. Basically, the specimen will experience tension before it breaks when the maximum limit is reached. In this work, a diametrical shape representing the tunnel boring machine (TBM) was selected. The rock samples was placed in perpendicular position to the tip of point load as shown in Figure 7, to portray the tension received from both direction of the tunnel. For a measurement of diametrical test, De is equivalent to D that represent the equivalent of core diameter. The corrected size of the point load index Is (50) is defined as Is if the $D_{e}$ is $50 \mathrm{~mm}$ [8]. Point Load Strength Index (Is) was measured by dividing the point load test value with the diameter core of the samples [9]. The UCS value is calculated by multiplying with the conversion factor as shown below;

$$
I s(50)=\frac{P}{D e^{2}}
$$

Where ;

$\mathrm{I}_{\mathrm{S}}=$ Corrected point load strength index (MPa or psi) $\mathrm{P}=$ Load failure, in $\mathrm{MN}$ or $\mathrm{lbf}$ (max pressure $\mathrm{x}$ jack piston area) 
$D_{e}=$ Equivalent core diameter (meters or inches)

$\left(D_{e}=D\right.$ for diametrical test $)$.

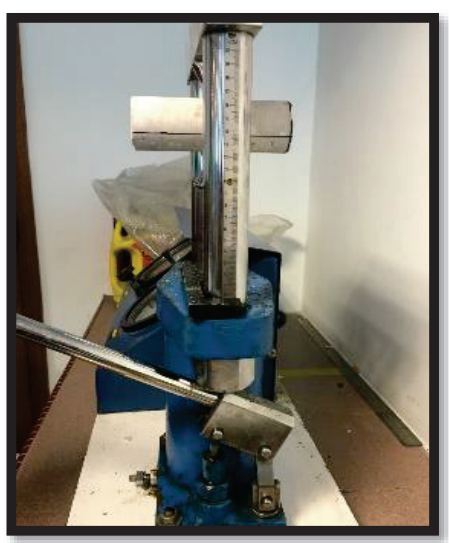

Fig. 7. The point load index test from the side view.

\section{Results and discussion}

\subsection{Weathering grade}

There are two types of rock weathering of rocks which are mechanical weathering and chemical weathering [10]. The weathering characteristics of the rock samples were assessed based on the physical appearances and colours. It was observed that most of the rock samples were yellowish- grey. According to the standard reference, the weathering index for the 14 rock samples were graded between Grade II and III. Figure 8 shows the two rock samples with different colours from box CUB 073, which indicated different grade of weathering. Sample F2 was light grey in colour indicating weathering grade II while B5 was yellowish grey in colour, indicating grade III of weathering.
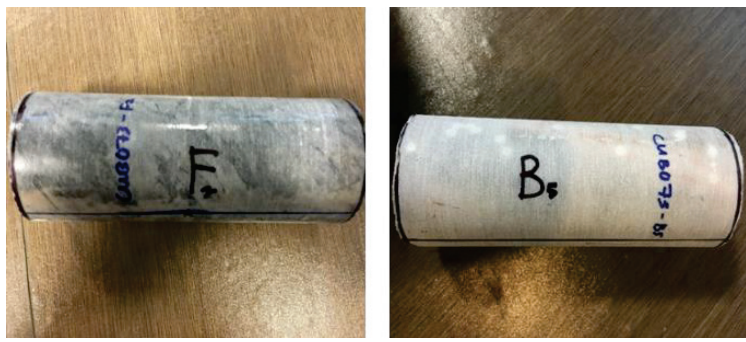

Fig. 8. Two different rock coring samples.

\subsubsection{Schmidt hammer test}

Table 1 showed the minimum UCS value which was $25.49 \mathrm{KPa}$ and the maximum value of UCS was 42.84 $\mathrm{KPa}$. According to the standard reference [11], Schmidt hammer index for limestone ranged around 35-51. But the UCS readings for some samples were slightly low due to the weathering factors.
Table 1. Results of Schmidt Hammer Test

\begin{tabular}{|c|c|c|c|c|c|c|c|}
\hline Sample & \begin{tabular}{|c} 
Average \\
value of \\
Schmidt \\
Hammer, \\
N \\
\end{tabular} & $\begin{array}{l}\text { UCS }= \\
4.24 \mathrm{e}^{\wedge} \\
0.059 \mathrm{~N}\end{array}$ & Mode & Mean & Median & $\begin{array}{l}\text { Min } \\
\text { UCS }\end{array}$ & $\begin{array}{l}\text { Max } \\
\text { UCS }\end{array}$ \\
\hline 1 & 32.4 & 28.68 & \multirow{15}{*}{39.2} & \multirow{15}{*}{33.8} & \multirow{15}{*}{34.6} & \multirow{15}{*}{25.49} & \multirow{15}{*}{42.84} \\
\hline 2 & 35.3 & 34.03 & & & & & \\
\hline 3 & 31.4 & 27.04 & & & & & \\
\hline 4 & 35.3 & 34.03 & & & & & \\
\hline 5 & 33.1 & 29.88 & & & & & \\
\hline 6 & 33.8 & 31.15 & & & & & \\
\hline 7 & 39.2 & 42.84 & & & & & \\
\hline 8 & 39.2 & 42.84 & & & & & \\
\hline 9 & 38.1 & 40.14 & & & & & \\
\hline 10 & 32.6 & 29.02 & & & & & \\
\hline 11 & 30.9 & 26.25 & & & & & \\
\hline 12 & 30.3 & 25.34 & & & & & \\
\hline 13 & 39.2 & 42.84 & & & & & \\
\hline 14 & 30.4 & 25.49 & & & & & \\
\hline 15 & 37.9 & 39.67 & & & & & \\
\hline
\end{tabular}

\subsubsection{Point load test}

The point load test showed that the rock sample, CUB 073- B5 had the highest value force at failure which was $6.69 \mathrm{kN}$ that gave the highest result of UCS value. The condition of the rock samples CUB 073-B5 after ruptured is shown in Figure 9.

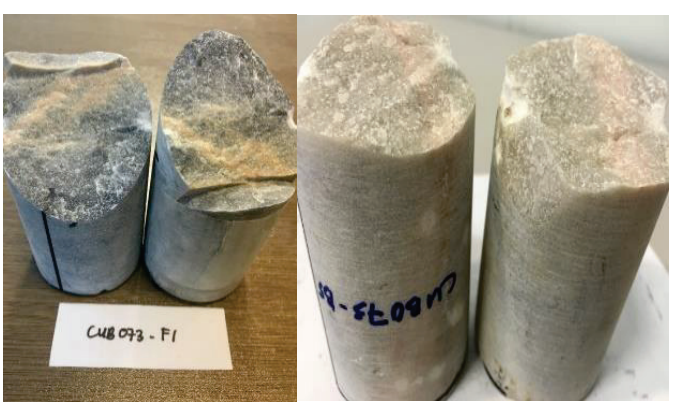

Fig. 9. Samples from CUB 073 and fractured after point load test.

\subsubsection{Geological survey to rock testing correlation}

For the analysis, geophysical surveys and borehole data were correlated with the laboratory results of rock testing. Seismic refraction and electrical resistivity tomography analysis were conducted along Line 1 . The data obtained from the experimental site showed that the surface wave velocity, Vs below $400 \mathrm{~m} / \mathrm{s}$ was inferred as low density medium whereas for Vs greater than 400 $\mathrm{m} / \mathrm{s}$ is considered high density medium. Therefore, the Vs with the approximate value $400 \mathrm{~m} / \mathrm{s}$ was interpreted as the interface between soil and rock layers. The result of MASW was further reconfirmed using the EI survey that was carried out at the same line. Figure 10 shows the comparison of MASW and EI colour range. 

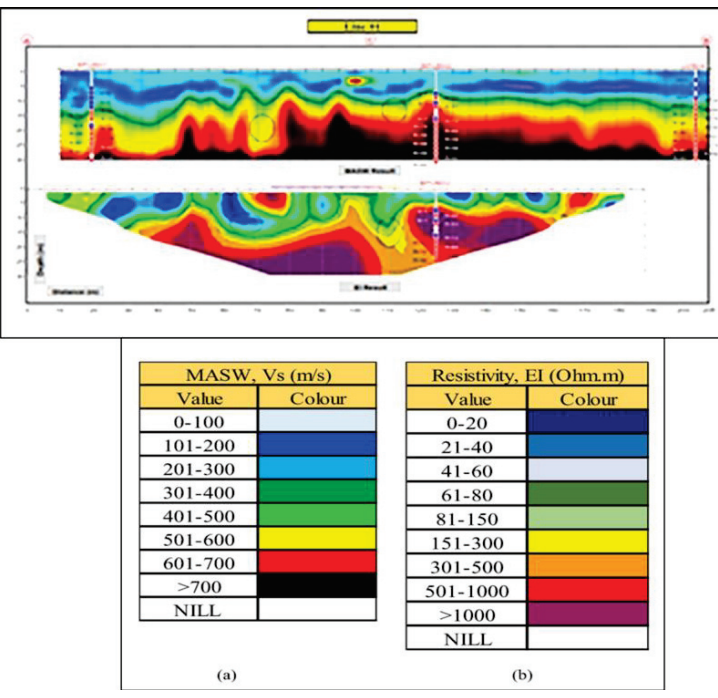

Fig.10. Seismic wave analysis.

\subsubsection{Borehole analysis}

The rock was identified at depth of $13.50 \mathrm{~m}$ at borehole BPU- BH1. The data of geophysical survey data showed that the carbonate rock was slightly weathered from 30 $\mathrm{m}$ to $36 \mathrm{~m}$ depth which only can be penetrated by surface wave velocity at this level. Meanwhile, analysis of surface wave velocity and electrical resistivity and were done at borehole $\mathrm{BPU}-\mathrm{BH} 2$. The results indicated that the rock was a little weathered at $17 \mathrm{~m}$ depth to $36 \mathrm{~m}$ depth. The electrical resistivity showed that the carbonate rock possessed the highest wave propagation at $9 \mathrm{~m}$ depth to $13.50 \mathrm{~m}$ depth. It was concluded that the rock sample at this borehole was intact without any fracture. As for borehole BPU-BH4 with rock from 10 $m$ depth, the velocities of the seismic refraction was measured from $300 \mathrm{~m} / \mathrm{s}$ up to $700 \mathrm{~m} / \mathrm{s}$ down to borehole depth. From this analysis, it can be deduced that, higher seismic value as it reach deeper into hard soil stratum.

\subsubsection{Graph Correlation between tests}

The correlation from the experimental results was obtained based on all collected data from the testing is tabulated in Table 2. The graph in Figure 11 shows that the regression between destructive and undestructive test was about 0.7648 meanwhile in Figure 12, the graph demonstrated higher velocity reading of rock as the density increased. Figure 14 shows the graph between the density of rocks and Schmidth hammer test. It shows that the regression between two is $\mathrm{R}^{2}=0.8468$ and Figure 15 show that the regression between the primary velocity and the uniaxial compressive strength gives the value of $\mathrm{R} 2=0.8592$, indicating that the rock is firm and intact with higher velocity.
Table 2. Summary of overall results

\begin{tabular}{|c|c|c|c|c|c|}
\hline & $\begin{array}{c}\mathrm{Vp} \\
(\mathrm{km} / \mathrm{s})\end{array}$ & $\begin{array}{c}\text { PLT } \\
(\mathrm{MPa})\end{array}$ & $\begin{array}{c}\mathrm{SH} \\
(\mathrm{kN})\end{array}$ & $\begin{array}{c}\text { Density } \\
\left(\mathrm{kg} / \mathrm{m}^{3}\right)\end{array}$ & $\begin{array}{c}\text { UCS } \\
\text { from } \\
\text { PLT } \\
(\mathrm{MPa})\end{array}$ \\
\hline 1 & 3.505 & 0.970 & 30.3 & 2.710 & 15.5 \\
\hline 2 & 4.319 & 0.970 & 30.4 & 2.753 & 15.5 \\
\hline 3 & 4.337 & 3.685 & 30.9 & 2.773 & 59.0 \\
\hline 4 & 4.557 & 3.685 & 31.4 & 2.781 & 59.0 \\
\hline 5 & 4.594 & 3.685 & 32.4 & 2.787 & 59.0 \\
\hline 6 & 4.62 & 4.170 & 32.6 & 2.789 & 66.7 \\
\hline 7 & 4.858 & 4.267 & 33.1 & 2.804 & 68.3 \\
\hline 8 & 5.088 & 4.461 & 33.8 & 2.815 & 71.40 \\
\hline 9 & 5.201 & 4.849 & 35.3 & 2.822 & 77.40 \\
\hline 10 & 5.302 & 5.237 & 35.3 & 2.828 & 83.80 \\
\hline 11 & 5.432 & 5.334 & 37.9 & 2.83 & 85.30 \\
\hline 12 & 5.596 & 5.528 & 38.1 & 2.842 & 88.40 \\
\hline 13 & 5.771 & 5.819 & 39.2 & 2.845 & 93.10 \\
\hline 14 & 5.845 & 6.750 & 39.2 & 2.857 & 108.00 \\
\hline 15 & 6.62 & & 39.2 & 2.862 & \\
\hline
\end{tabular}

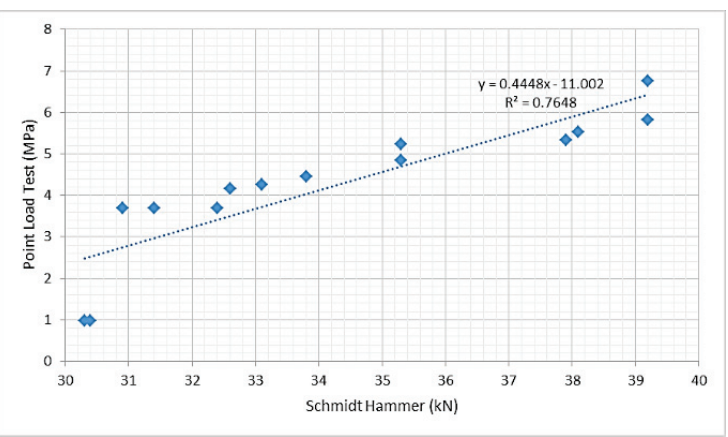

Fig. 11. Graph of Schmidt hammer vs point load index test.

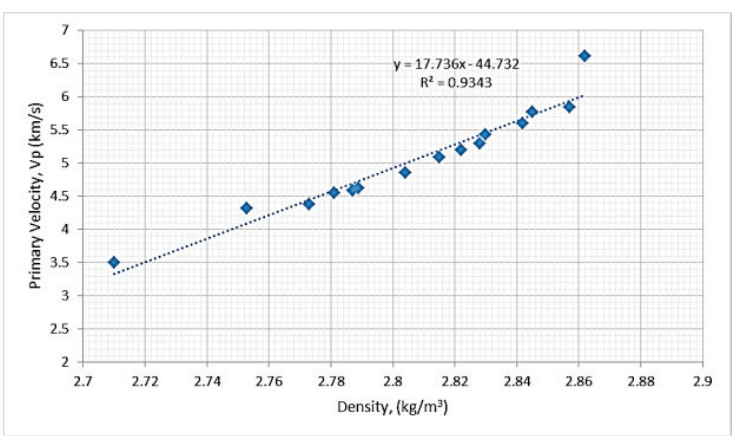

Fig. 12. Graph of density vs primary velocity.

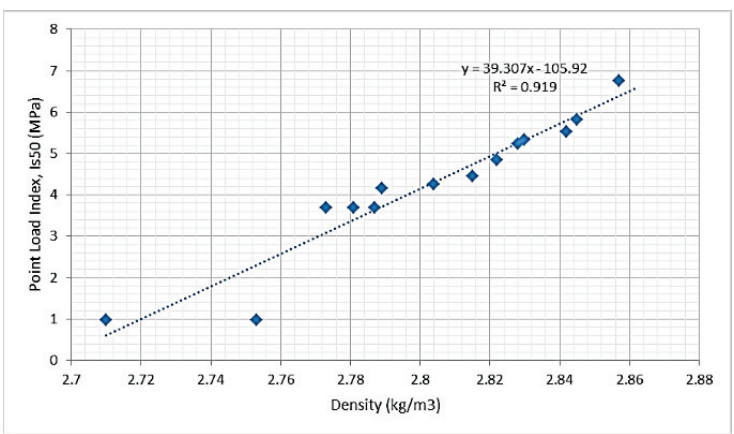

Fig. 13. Graph of density vs point load index test. 


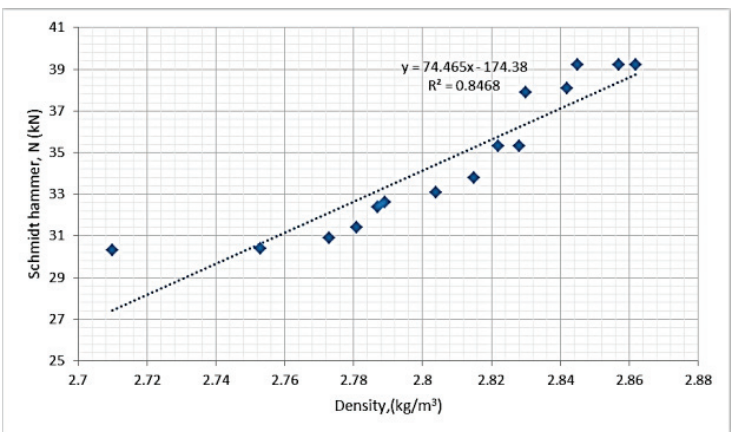

Fig. 14. Graph of density vs Schmidt hammer.

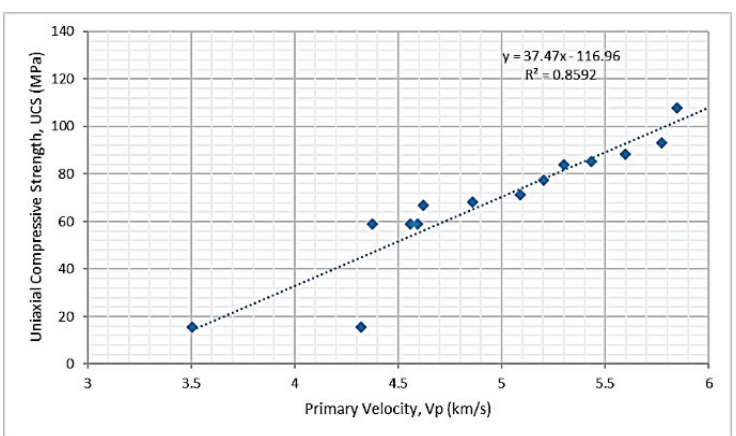

Fig. 15. Primary velocity, Vp vs UCS of Point Load Index

\section{Conclusion}

This work investigated the subsurface tomography of a proposed site for tunnel construction by collecting information on borehole data and seismic refraction survey. The results showed that most of the subsurface rocks were made up of limestone. Based on the physical observation and visual test, most of the rock samples with yellowish-grey colour were classified in the weathering grade II and the rocks with light grey colour rocks were classified in class III. In conclusion, the data collected from the UCS of the rock samples can be used as a reference for the design of rock tunnelling project and construction.

The author would like to thank UNITEN's Innovation \& Research Management Centre (iRMC) for funding this study through research grant 20200102CRGJ. The author would like to thank the Department of Environmental Geography, Faculty of Geography, for their assistance in interpretation, as well as Gamuda Bhd for providing samples for this study.

\section{References}

1. A. A. El Aal, Egyptian Journal of Petroleum 26, 3:565-578 (2017)

2. L. Zhang, Engineering properties of rocks, (The American Institute of Architects (AIA), Butterworth-Heinemann, 2016)

3. H. Zabidi, N. L. Khalil, N. E. Q. M. Anua, S. Suri, Journal of Physics: Conference Series 1242, 1:012044 (2019)
4. H. Zabidi, M. H. De Freitas, Engineering Geology 117, 3-4:159-169 (2011)

5. G. T. Lai, A. S. Serasa, A. G. Rafaek, N. Simon, A. Hussin, T. R. T. Mohamed, L.K. Ern, Electronic Journal of Geothechnical Engineering, 22:1681-1692 (2017)

6. D. Stead, A. Wolter, Journal of Structural Geology, 7: 1-23 (2015)

7. T. Yilmaz, B. Ercikdi, Nondestructive Testing and Evaluation 31, 3:247-266 (2016)

8. A. Aydin, International Journal of Rock Mechaics and Mining Series 46, 3:627-634 (2009)

9. M. Akram, M. A. Bakar, Pakistan Journal of Engineering and Applied Sciences (2016)

10. G. Vlastelica, P. Miščević, N. Pavić, Gradevinar, 68, 12:955-965 (2016)

11. E. Hoek, E. T. Brown, J Geotech. Engng Div, 16-28 (1980) 